\title{
Burning of substandard liquid hydrocarbons with steam gasification
}

\author{
Igor Anufriev ${ }^{1, *}$, Sergey Arsentyev ${ }^{1,2}$, Mikhail Vigriyanov ${ }^{1}$, Evgeny Kopyev ${ }^{1}$, and \\ Oleg Sharypov ${ }^{1}$ \\ ${ }^{1}$ Kutateladze Institute of Thermophysics SB RAS, Novosibirsk, Russia \\ ${ }^{2}$ Novosibirsk State University, Novosibirsk, Russia
}

\begin{abstract}
The characteristics of burning of substandard liquid hydrocarbons in a direct-flow evaporative burner with controlled forced jet feeding of superheated steam are studied by the example of waste transmission automobile oil. The influence of the steam regime parameters on the temperature distribution in the flame, the thermal power and the composition of the combustion products is determined. The regimes providing simultaneously a low concentration of $\mathrm{CO}$ and $\mathrm{NOx}$ and a high power of heat release have been found.
\end{abstract}

At present, high attention is paid to environmental safety. 2017 is declared as the year of the ecology in Russia. An important problem is the disposal of a large volume of liquid hydrocarbon wastes (waste oil and lubricating fluid, remains of substandard fuels, and refinery waste, etc.) accumulated in enterprises of thermal energy sector and other industries. These wastes have not found wide practical application and carry a significant danger of the environmental pollution. The wide use of such hydrocarbons for replacing high-quality organic fuels is hampered by the non-compliance between the existing technologies and environmental requirements, their insufficient energy efficiency, problems associated with fuel ignition, coking of surfaces, etc. In this regard, of interest is to search for and scientifically substantiate new ways of burning substandard liquid hydrocarbons, and to develop and create power plants, effectively utilizing such fuel to obtain thermal energy.

One of the promising technologies is burning of low-quality liquid hydrocarbon fuels in the presence of superheated steam [1,2]. Preliminary studies [3, 4] conducted in the IT SB RAS by the example of burning diesel fuel in original autonomous burner devices of evaporative type with $10-50 \mathrm{~kW}$ power $[5,6]$ have shown that when feeding superheated steam jet into the combustion zone, the combustion of liquid hydrocarbons sharply intensifies, providing steady ignition at high fuel consumption. In the process of gasification, intermediate components $\mathrm{CO}$ and $\mathrm{H}_{2}$ are formed. It is shown that soot is practically absent in the combustion products, and its content in the combustion products is $35 \mathrm{mg} / \mathrm{m}^{3}$ [7]. The use of autonomous burners during the experiments provides constant values of the steam state parameters $[5,6]$, but does not allow obtaining data on the regularities necessary for physical justification of effective control over the process.

*Corresponding author: anufriev@itp.nsc.ru 
Developing previous studies [3, 4], this paper experimentally investigates the combustion of liquid hydrocarbons with controlled forced supply of the superheated steam jet to the combustion zone by the example of waste transmission automobile oil. The aim is to study the influence of regime parameters (flowrate and temperature of steam) on the main characteristics of the process.

The research was carried out on an automated fire stand (Fig. 1), equipped with an original direct-flow evaporative-type burner (up to $10 \mathrm{~kW}$ ), an electric steam generator (average power consumption of $1.5 \mathrm{~kW}$ ), a plunger dosing pump (flow rate up to $1.6 \mathrm{l} / \mathrm{h}$ ), a steam generator control system, a heating and fuel supply system, electronic scales for controlling the consumptions of water and fuel, as well as the necessary instrumentations.

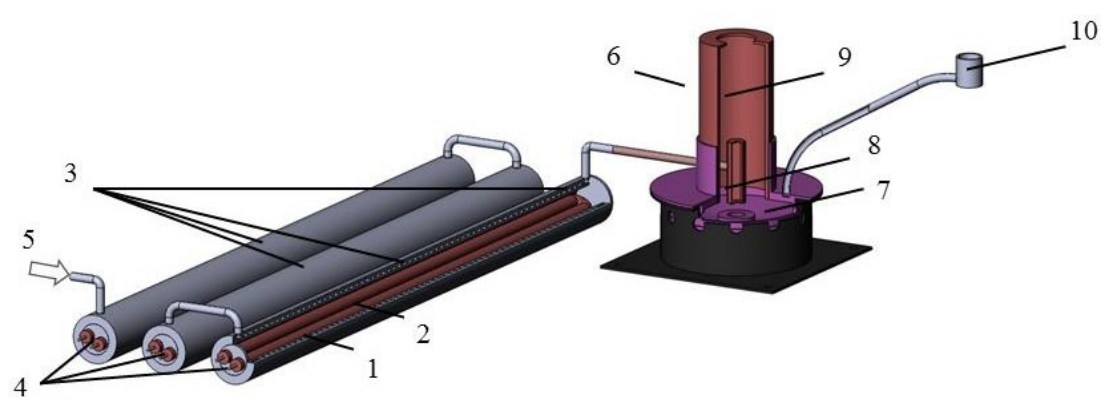

Fig. 1. Scheme of burner device and steam generator: 1 - steam generator; 2 - electric heater; 3 -thermocouples; 4 - heater power terminals; 5 - water supply; 6 - burner; 7 -combustion chamber; 8 - steam injector; 9 - gas generation chamber; 10 - fuel receiver with fuel pipeline.

The main elements of the burner are: a cylindrical body, a combustion chamber, a steam nozzle and a gas generation chamber. All elements are made of $12 \mathrm{X} 18 \mathrm{H} 10 \mathrm{~T}$ steel. There are openings for natural air inflow from the atmosphere in the lower part of the combustion chamber. Since the burner is of evaporative type, it is necessary to ensure high-viscosity fuels preheating for their stable ignition. For this, a fuel heating system (up to $60{ }^{\circ} \mathrm{C}$ ) based on electric heaters is used. Fuel is transferred to the combustion chamber through the fuel line. Stable fuel consumption is set by the fuel injector and pump. The steam nozzle is installed coaxially above the combustion chamber at the base of the gas generation chamber and is oriented vertically (output diameter of $0.5 \mathrm{~mm}$ ). The steam nozzle is connected to an external steam generator. The laboratory electric steam generator allows obtaining superheated steam in the range of temperatures $T=150-550{ }^{\circ} \mathrm{C}$ and consumptions $F=0.25-1.5 \mathrm{~kg} / \mathrm{h}$ (at pressures up to $10 \mathrm{~atm}$ ). The scheme of the combustion process is similar to an autonomous burner [3]. The chemical composition of the used fuel is as follows: mass fractions of carbon $-84.24 \%$, hydrogen $-13.48 \%$, oxygen $-1.55 \%$, and nitrogen $-0.73 \%$.

With constant fuel consumption $F_{f}=0.675 \mathrm{~kg} / \mathrm{h}$, the value of $\gamma=F / F_{f}$ was varied from 0.31 to 1.38 . At these values of $\gamma$, steady combustion was provided (Fig. 2). In previous studies of diesel fuel combustion, the influence of the steam superheating temperature on $\mathrm{CO}$ and $\mathrm{NO}_{\mathrm{x}}$ concentration was not observed in combustion products. Therefore the measurements were carried out at a constant temperature of the superheated steam $T \sim 250{ }^{\circ} \mathrm{C}$ (at the pressure of $2.5-8.0 \mathrm{~atm}$ ).

Using platinum-rhodium/platinum-rhodium thermocouple, temperature profiles were obtained in the outer flame along the vertical axis of the burner (Fig. 3). Almost in all regimes, the maximum temperature in the flame reached $1400{ }^{\circ} \mathrm{C}$ and decreased with decreasing $\gamma$. The characteristic longitudinal size of the luminous zone ("length of the torch") varies from $0.27 \mathrm{~m}$ to $0.1 \mathrm{~m}$ with the increase in $\gamma$ from 0.31 to 1.38 (Fig. 2). With 
increasing $\gamma$ and reducing flame length, the region with the maximum temperature approached the burner outlet (Fig. 3).

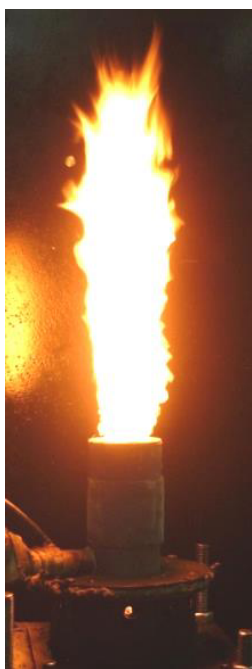

(a)

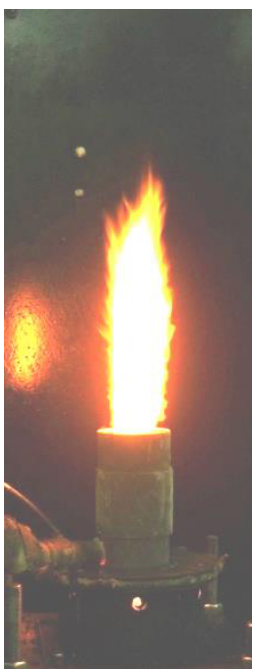

(b)

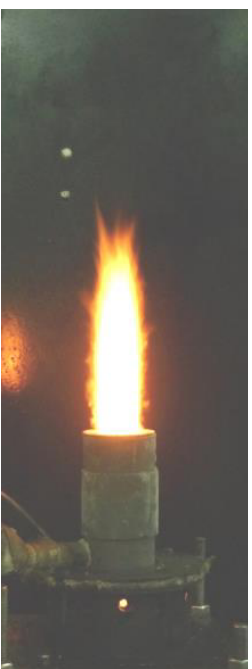

(c)

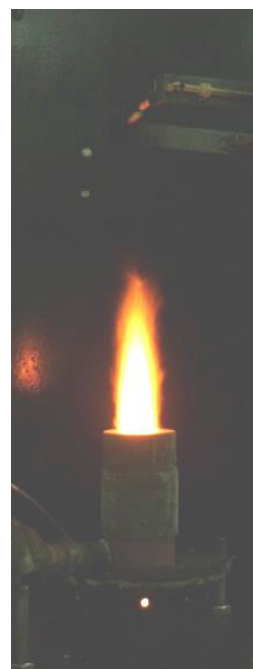

(d)

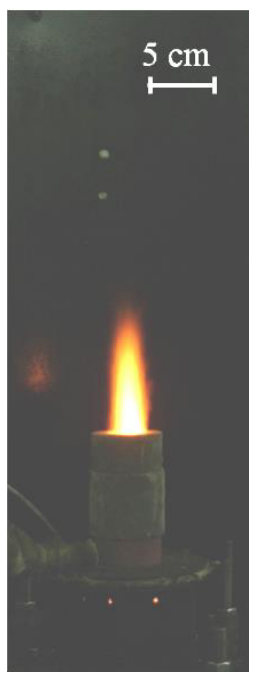

(e)

Fig. 2. Combustion of waste transmission automobile oil in the direct-flow evaporative burner at various superheated steam consumption $\left(T \sim 250{ }^{\circ} \mathrm{C}\right)$ : (a) $\gamma=0.31$; (b) $\gamma=0.54$; (c) $\gamma=0.75$; (d) $\gamma=0.97$; (e) $\gamma=1.38$.

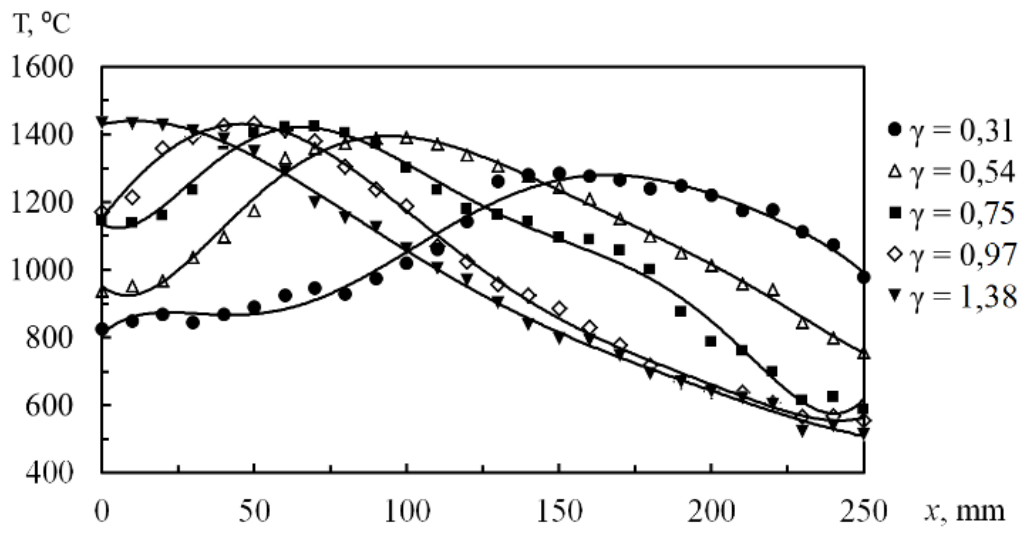

Fig. 3. Distribution of the time-averaged temperature in the outer flame along the vertical axis of the burner at different consumption of superheated steam, $T=250{ }^{\circ} \mathrm{C}$.

The thermal power of the burner device in the investigated range of steam parameters was measured with a flow calorimeter [3]. The specific heat and power were determined under stationary experimental conditions from a difference between the coolant (water) temperatures at the inlet and outlet and the consumptions of the coolant and fuel. The results showed that within the measurement error, the specific heat release (per $1 \mathrm{~kg}$ of fuel) did not depend on steam consumption and was $q=45 \mathrm{MJ} / \mathrm{kg}$ at a power of $8.5 \mathrm{~kW}$. When calculating the specific heat, the energy received by the water in the steam generator was subtracted. 


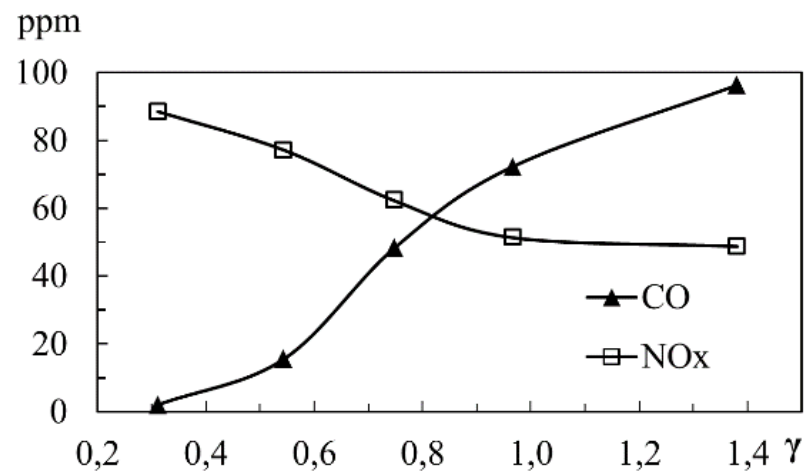

Fig. 4. $\mathrm{CO}$ and NOx concentrations at different ratio of steam and fuel consumption, $T=250{ }^{\circ} \mathrm{C}$.

Gas analyzer TESTO 350 was used to control the composition of the combustion products $\left(\mathrm{O}_{2}, \mathrm{CO}, \mathrm{NO}, \mathrm{NO}_{2}, \mathrm{SO}_{2}, \mathrm{CO}_{2}\right)$. The studies were conducted simultaneously with the calorimetric measurements. The reaction products (cooled to ambient temperature) were sampled at the calorimeter outlet. For all studied regimes, the $\mathrm{CO}$ and $\mathrm{NO}_{\mathrm{x}}$ content in the flue gases was significantly lower than the maximum allowable concentration level (Fig. 4). For the given fuel consumption, the value of steam consumption $(\gamma \approx 0.8)$ provides low concentrations of $\mathrm{CO}$ and $\mathrm{NO}_{\mathrm{x}}$ simultaneously with high thermal output.

Research was supported by the Russian Science Foundation (Project No. 17-79-20209).

\section{References}

1. S.V. Alekseenko, S.E. Pashchenko, V.V. Salomatov, J. Eng. Phys. Thermophys. 83, 729 (2010)

2. M.S. Vigriyanov, V.V. Salomatov, S.V. Alekseenko, RF Patent 2219435 (2003)

3. S.V. Alekseenko, I.S. Anufriev, M.S. Vigriyanov, E.P. Kopyev, O.V. Sharypov, Combust. Expl. Shock Waves 52, 286 (2016)

4. S.V. Alekseenko, I.S. Anufriev, M.S. Vigriyanov, V.M. Dulin, E.P. Kopyev, O.V. Sharypov, Thermophys. Aeromech. 21, 393 (2014)

5. M.S. Vigriyanov, S.V. Alekseenko, Anufriev, O.V. Sharypov, RF Patent 2579298 (2016)

6. M.S. Vigriyanov, S.V. Alekseenko, Anufriev, O.V. Sharypov, RF Patent 2523591 (2014)

7. I.S. Anufriev, A.M. Baklanov, O.V. Borovkova, M.S. Vigriyanov, O.V. Sharypov, Combust. Expl. Shock Waves 53140 (2017) 